\title{
Crowdfunding Models, Strategies, and Choices Between Them
}

\author{
Rotem Shneor
}

\section{Introduction}

During the last decade, the emergence and growing popularity of crowdfunding were manifested and promoted through the proliferation of thousands of online crowdfunding platforms worldwide. A crowdfunding platform is "an internet application bringing together project owners and their potential backers, as well as facilitating exchanges between them, according to a variety of business models" (Shneor and Flåten 2015, p. 188). According to Méric et al. (2016) most platforms have the following characteristics in common: first, providing fundraisers with campaign presentation formats for their project, which is accessible to all online users; second, allowing small to medium sized financial transactions that enable widespread participation while keeping risks within reasonable limit; and, third, provide relevant financial information about

R. Shneor $(\bowtie)$

School of Business and Law, University of Agder, Kristiansand, Norway e-mail: rotem.shneor@uia.no 
the campaign and its progress, as well as communication tools for interaction between prospective backers and fundraisers. In addition, some platforms also provide advice, social media PR functionalities, as well as referrals to other supporting services (ibid.).

The operation of platforms is overseen by regulation in each national jurisdiction (Gajda 2017). In addition, self-regulation is also evident through codes of conduct developed by industry associations for their member platforms (Wenzlaff and Odorovic 2020), as well as in rules and procedures developed by platforms themselves for own campaign approval and user verification. Nevertheless, dependency on legal compliance often results in a more constrained scope of operation both in geographical and functional terms. Here, while some platforms have developed into global giants (i.e. Kickstarter, Indiegogo, Gofundme, etc.) or regional actors (i.e. Latvia-based Mintos covering Eastern Europe, Finland-based Investor covering the Nordic countries, etc.), thus far, most platforms remain local and have a domestic focus or very limited international scope of activities (regulatory and international aspects of platform operations will be covered in greater detail in later chapters).

At this stage, it is also worth noting that in addition to platforms, crowdfunding activity also exists in the form of 'individual crowdfunding campaigns' (Belleflamme et al. 2013), which are individual- or organization-specific fundraising efforts carried outside formal platform control and oversight. However, due to the latter's sporadic nature, nonsystematic approach, and limited scope within private networks, most research documents crowdfunding with respect to platform activities and not with respect to individual campaigning efforts.

In the current chapter we present crowdfunding model types and their different characteristics. This will be followed by a discussion of how fundraisers may choose the best crowdfunding model for their own project's fundraising needs. The chapter will then conclude by highlighting its main contributions, limitations, as well as implications for research and practice. 


\section{Crowdfunding Models: A Typology}

Earlier studies have suggested a number of typologies for capturing the differing value propositions, practice patterns, funder motivations, risks and legal compliance needs of crowdfunding platforms (i.e. Haas et al. 2014; De Buysere et al. 2012; Méric et al. 2016; Belleflamme and Lambert 2016). We build on these earlier references but use the mostcomprehensive typology currently employed by the Cambridge Centre for Alternative Finance (CCAF) in its annual industry reports (Ziegler et al. 2018b, b, d, 2019; Zhang et al. 2018) and further elaborate on it. This typology is outlined in Table 2.1.

The first model of online crowdfunding to emerge was debt-based, in what is known as peer-to-peer (P2P) or marketplace lending, with the establishment of platforms like Zopa in the UK and Prosper in the USA in 2005. In the CCAF typology, debt-based models include non-deposit taking platforms that facilitate online credit (both in the form of a secured and unsecured loan) to individuals or business borrowers from individuals or institutional investors. In this respect, the platform functions as an intermediary. In some cases, known as balance sheet lending, one can observe a departure from original conceptualization of debt-based crowdfunding, where the platform serves as the loan-provider, drawing upon funds in a dedicated platform balance-sheet. In this respect, the platform goes beyond the role of intermediary facilitating exchanges between lenders and borrowers, and actively funds and services the loan.

A unique sub-set of lending included in the above is what is referred to as 'pro-social lending', which may, but not necessarily, take the form of micro-finance. Here, pro-social lending happens when lenders evaluate prospective borrowers on both traditional financial lending criteria and prosocial, charitable criteria (Allison et al. 2015). Prosocial loans relate to either consumer or business loans and may involve high as well as low sums, while catering projects with social welfare, human development, or environmental well-being and sustainability objectives. Thus, microfinance can be considered as a sub-set of prosocial loans specifically when loans involve small sums catering to economically disadvantaged and 


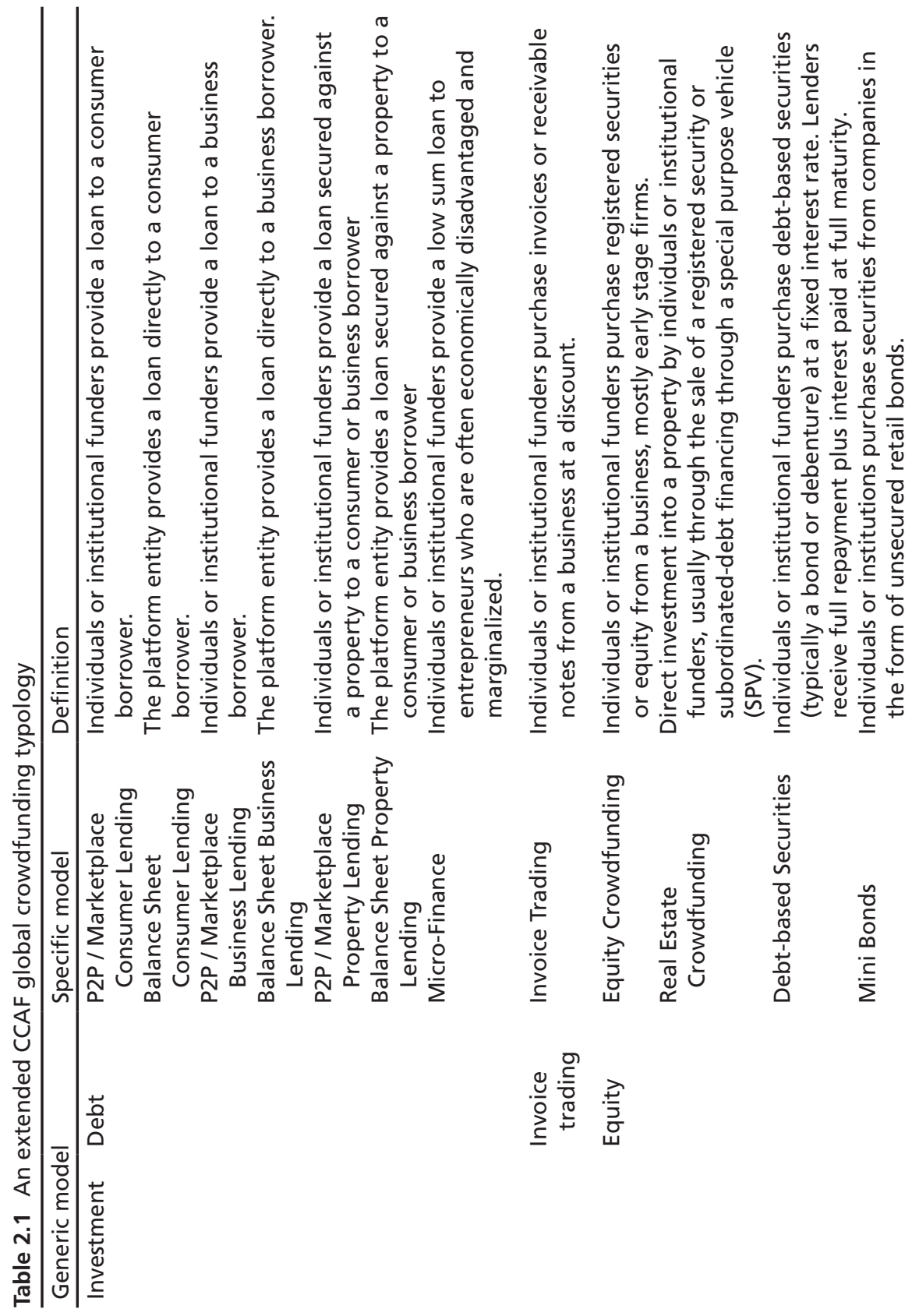




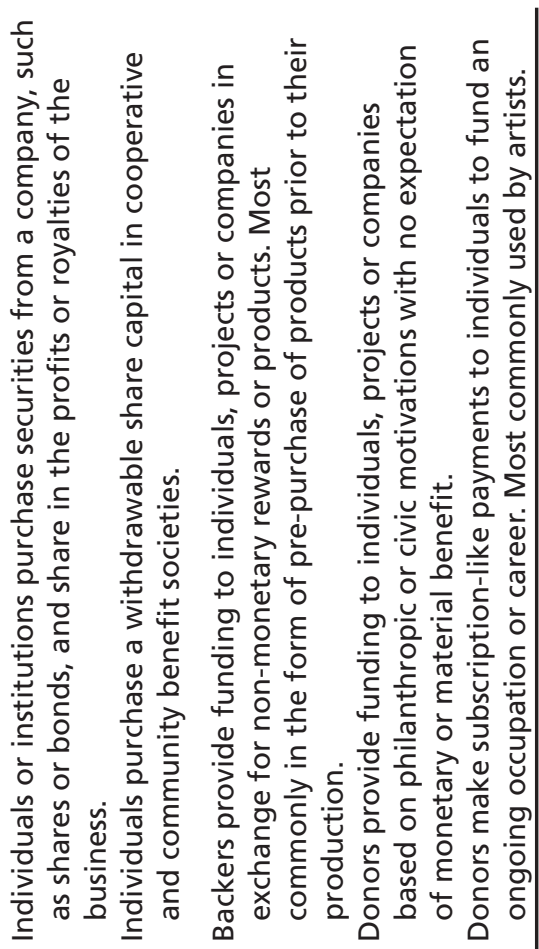

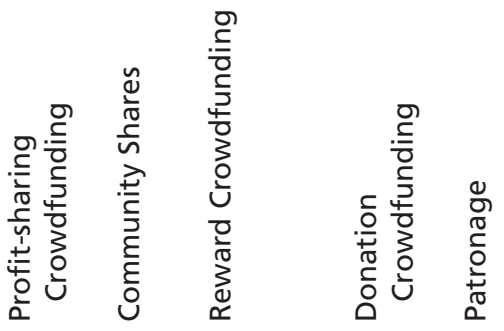

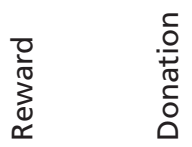

ㄷ․ 
financially marginalized individuals aiming "to improve the well-being of the poor through better access to savings services and loans" (Schreiner 2001).

Equity-based models, including equity crowdfunding, relate to activities where individuals or institutions invest in unlisted shares or debtbased securities issued by a business, typically an SME. Here, entrepreneurs make an open call to sell a specified amount of equity or bond-like shares via the internet in the hope of attracting a large number of investors (Ahlers et al. 2015). As equity-based models have advanced, more diversified applications have emerged beyond venture funding. Here, subsets of the model like Real Estate and Property-based crowdfunding have flourished, with investors able to acquire ownership of a property asset via the purchase of property shares.

Another interesting variant of the equity model relates to community shares, also referred to as the cooperative model. Under this model, funders' investments are collected to support a community project. And while some revenue-generating community projects have the potential of repaying backers wishing to cash-in their shares, most funders are motivated by investing in their local community rather than in financial returns (Gray and Zhang 2017).

A more recent addition to the crowdfunding models has been invoice trading, which is considered as a "fast and easy way in which small and medium sized enterprises (SMEs) can raise short-term debt by prefinancing their outstanding invoices through individual or institutional investors" (Dorfleitner et al. 2017, p. 56.). Such a short-term supply of financing, in which companies sell their accounts receivables at a discount in exchange for immediate cash, helps in alleviating cash-flow challenges that often affect SMEs. Hence, unlike other crowdfunding models, this specific model is less about fundraising per se, and more about cashflow management that is financed through crowd investments.

Finally, the reward and donation crowdfunding models, are arguably the models most commonly recognized by the public. In the case of these two models, individuals provide funding to a project, an individual, or a business without expectations of monetary returns for the funds raised. Here, while reward models often represent pre-sales of products and services, which funders expect to receive within a certain time frame, in donation, there are no tangible rewards, and funders are likely to have a 
sense of satisfaction from contributing to something they deem important and are passionate about. One interesting variant of donation crowdfunding captured above is patronage, which involves subscription-like payments (rather than a one-time donation) to individuals to fund an ongoing occupation or career and is of particular relevance for artists (Swords 2017), despite being relatively marginal in the overall crowdfunding sphere thus far.

While the above list of models presents a clear distinction between them, it is important to acknowledge that some platforms offer combinations of models, either as experiment or extensions of their services. These have been labelled as 'Hybrid Models' (De Buysere et al. 2012), and while not representing main stream practice, may offer extra benefits to funders and fundraisers alike. One example here may be a combination of equity and rewards campaign, where an equity investment may also incorporate special benefits for investors as consumers of the products produced by the firm that they are investing in.

In an attempt to simplify matters, and at the most basic of levels, Belleflamme and Lambert (2016) suggest a distinction between 'investment models' and 'non-investment models' defined based on the nature of compensation promised to, and expected by, funders. Accordingly, non-investment models include reward and donation crowdfunding, while investment models include lending and equity models (including royalty models such as profit or income sharing). In addition, one should add the relatively newer model of invoice trading to investment models of crowdfunding.

An additional, simple distinction between platforms is that distinguishing between two types of fundraising strategies. One, labelled as the 'all or nothing' (AON) approach, where fundraisers receive the funds raised only if the campaign has reached its stated minimum goal, otherwise funds are either returned or not charged from backers. The second, labelled as the 'take it all' (TIA) approach, where fundraisers receive the funds raised regardless of whether the campaign reached its stated minimum sum goal or not. The prevailing approach across models is the former, as it may signal greater levels of commitment and seriousness. Nevertheless, the latter is a popular approach in donation and pro-social lending, where some welfare improvement is preferable to none. 
Interestingly, research examining the two approaches in the specific context of reward crowdfunding has shown that $\mathrm{AON}$ forces fundraisers to bear greater risk but serves as a signal of commitment, which in turn yields higher quality campaigns and greater success rates (Cumming et al. 2019b).

A different typology suggested by Haas et al. (2014), identifies three archetypes of crowdfunding intermediaries by their different value propositions-Hedonism, Altruism, and For-Profit. Hedonism platforms are those where backers pledge for innovative or creative products or projects with consumption in mind, all while addressing individuals' interests and sense of joy. These are mostly associated with the Reward crowdfunding model. Altruism platforms are those where backers pledge for a 'greater good' or 'enhanced welfare' and are mostly associated with donation or pro-social lending platforms but can also relate to community shares. For-profit platforms are those where backers pledge for a profit-oriented return and are associated with equity, royalty (profit sharing), and lending platforms to which one can also add invoice trading.

Nevertheless, the most popular generic classification of crowdfunding models has thus far included-equity, lending, reward and donation (Méric et al. 2016). We suggest adding invoice trading to this generic classification, as it presents a unique new model that only in recent years became significant in volumes in multiple markets, accounting for $22 \%$ of the 2017 annual crowdfunding volumes in Latin America (Ziegler et al. 2018b), 18\% in the UK (Zhang et al. 2018), and 16\% in mainland Europe (Ziegler et al. 2019).

\section{Crowdfunding Models: Key Characteristics}

Once the models have been defined, it is important to establish an understanding of their characteristics. Table 2.2 summarizes the key characteristics of each model while providing illustrative figures whenever available from earlier research and industry reports.

Equity models are associated with the highest levels of funds raised, while involving projects with a long time horizon and some of the highest levels of risk, although the latter remains uncertain as available data capture ventures that have entered the equity crowdfunding market at its 


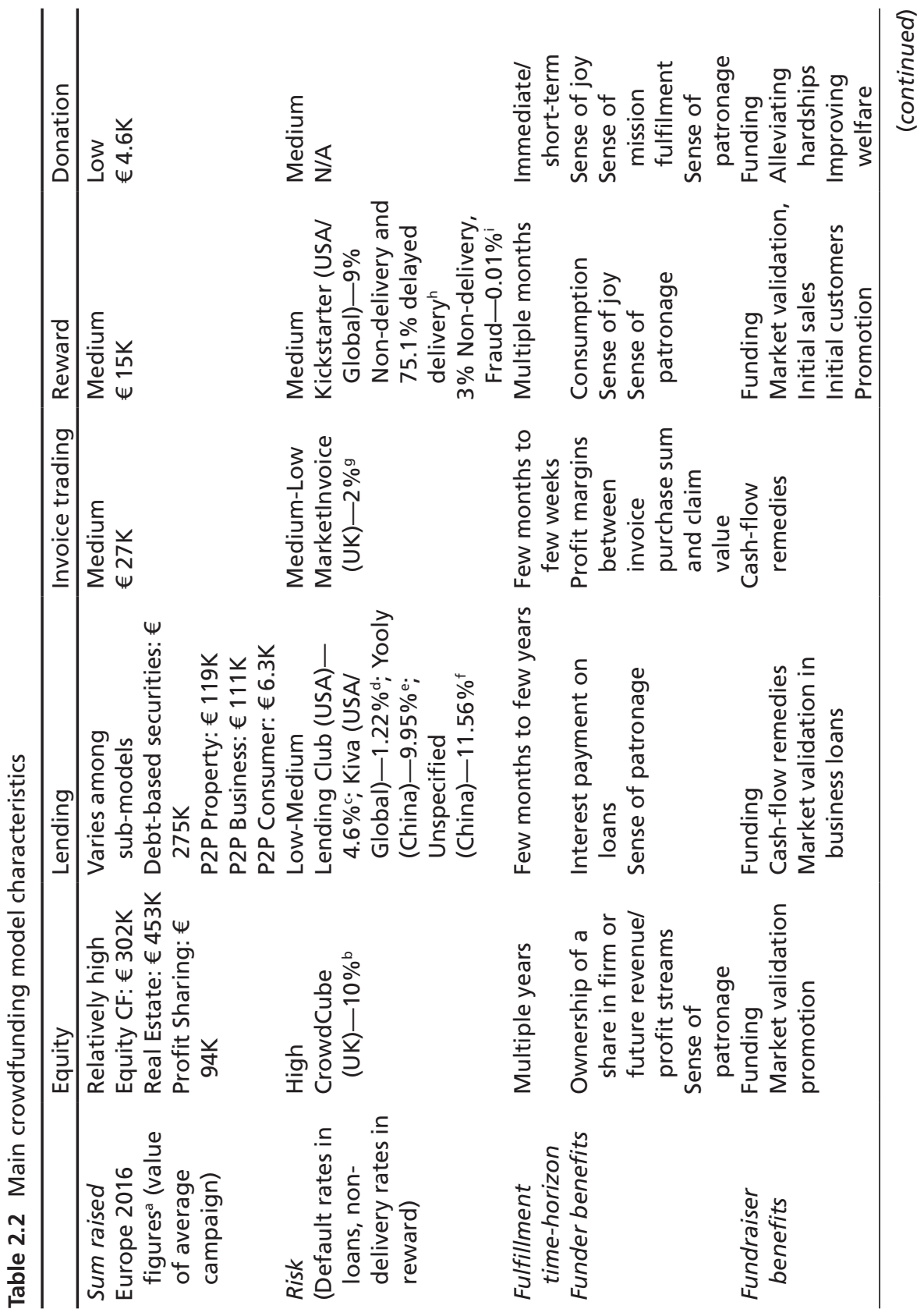




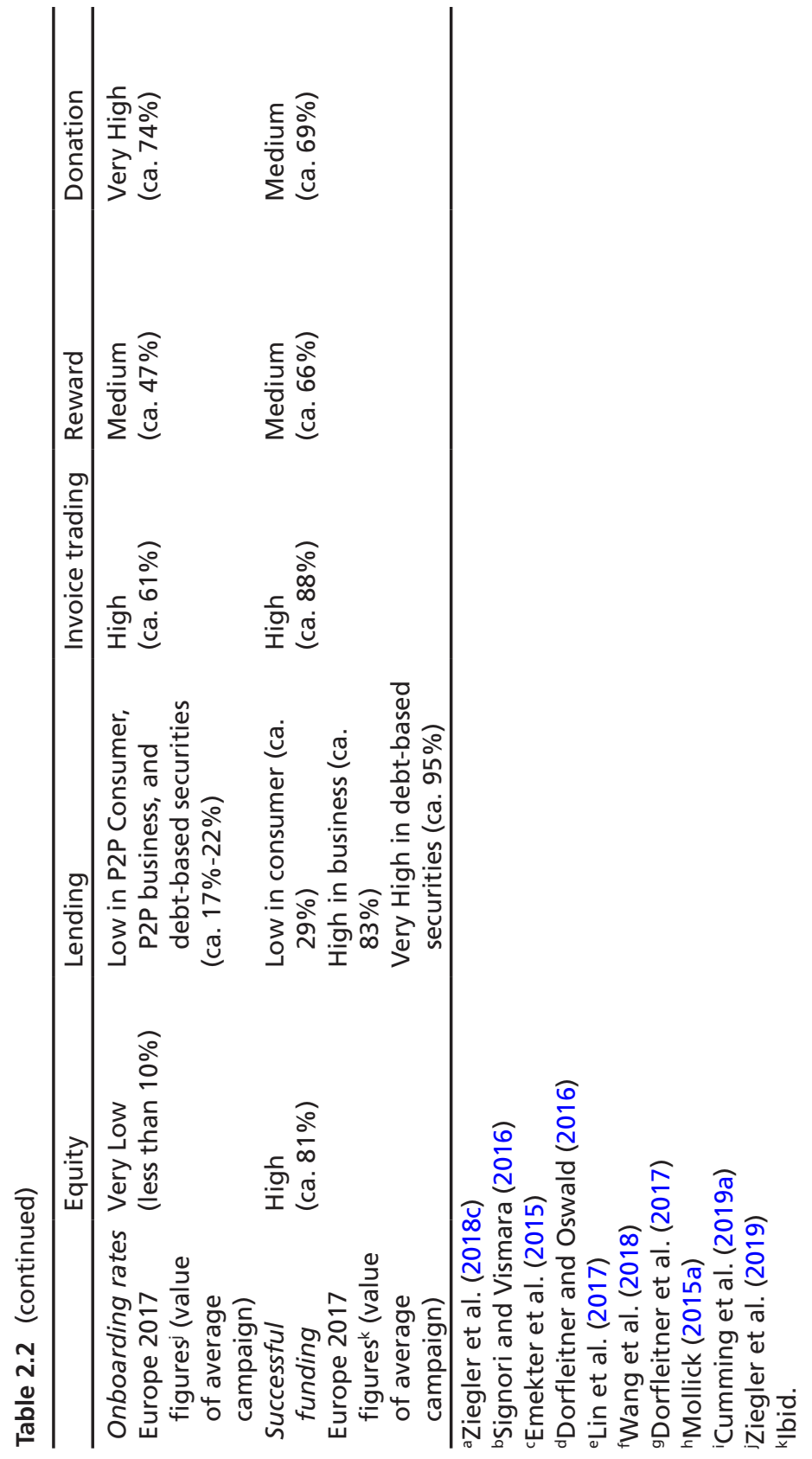


very early stages. Well-reflective of the risk levels involved, as well as strict regulations governing this model, platforms employ high levels of filtering efforts, with only a small minority of suggested projects being approved for publication and live campaigning (otherwise known as onboarding rate). However, as a result, equity models also present some of the highest success rates among campaigns approved for publication across all models.

The characteristics of lending models are more diverse based on the model employed and the target audience served. Debt-based securities involve the highest volumes raised on average per campaign, low onboarding rates, and very high success rates. On the other hand, P2P consumer lending involves relatively low sums, and despite low onboarding rates, has some of the lowest success rates across all models, as well as some of the highest recorded default rates. An exception here are micro-finance loans exhibiting some of the lowest default rates among all lending models.

Invoice trading is characterized by low default rates, relatively high onboarding, and very high success rates. This may be related to the relative novelty of the model, where platforms need to achieve legitimacy in the market, as well as the fact that transactions tend to involve relatively modest sums in a grander business financing context.

Reward crowdfunding, however, involves more modest sums and is associated with medium onboarding rates and levels of success. Here, while outright fraud is extremely rare, and non-delivery levels remain low, late delivery is a major aspect of fulfilment on reward crowdfunding campaign promises. Delays were frequently associated with either very small sums or very large sums raised (Mollick 2015b). In the former, entrepreneurs are likely to face higher costs than expected, which may delay production and delivery. And in the latter, entrepreneurs may face overfunding and high demands which generate complexities requiring more time to overcome by relatively small businesses (Hainz 2018).

Finally, donation crowdfunding is associated with the lowest sums raised per campaign on average, and is characterized by relatively high onboarding rates, and medium success rates in comparison to other models. However, being one of the least studied crowdfunding models and offering no tangible benefit in return for funds raised, it is more difficult to assess the extent of non-delivery or fraudulent activities under this model. 


\section{Fundraiser Model Choice}

Once the models have been defined and outlined, and their characteristics presented, prospective fundraisers need to choose the best fitting model for their respective projects. In the current section decision-making frameworks are suggested to guide fundraisers through key considerations when making such choices, based on establishing a good fit between funding needs and each model's characteristics. In total, three frameworks are presented. Figure 2.1 presents the 'Generic Organizational Fundraiser Model Choice Framework'. Figure 2.2 presents its more elaborate version labelled as the 'Extended Organizational Fundraiser Model Choice Framework'. Here, the extended framework incorporates the generic framework. The former is provided for simplification purposes as it covers the most familiar crowdfunding models, while the latter also incorporates newer or less familiar models. In any case, the focus here is on organizations without limitations on size (from micro-entrepreneurs to large businesses) or sectoral affiliation. In addition, Fig. 2.3 presents the "Consumer Fundraiser Model Choice Framework", reflecting individuals with fundraising for non-business private consumption needs.

First, from the perspective of the organizational fundraiser, both the generic and the extended frameworks present relevant guidelines. Here,

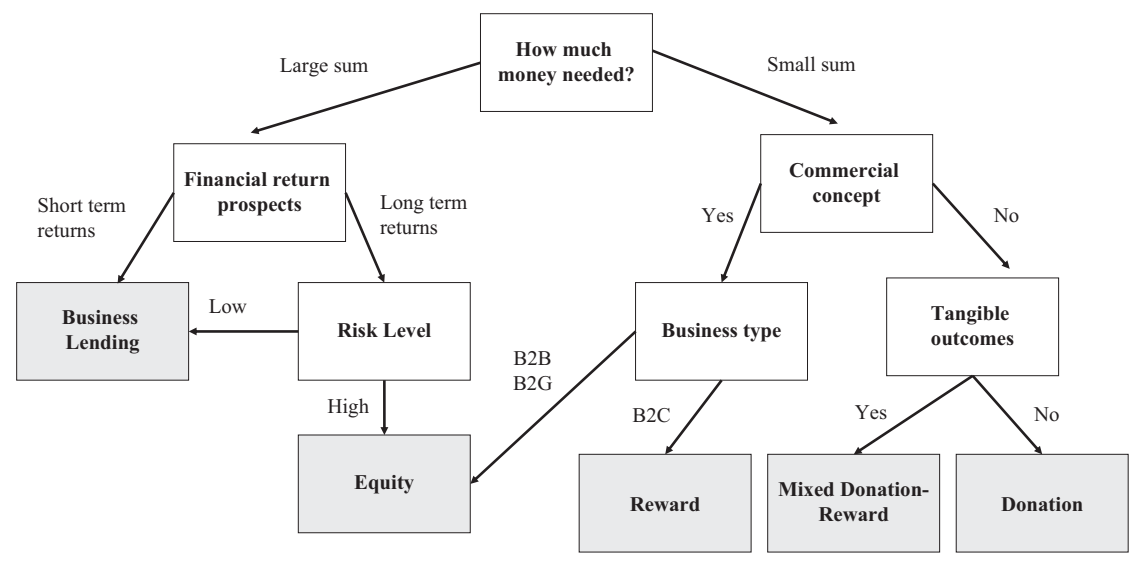

Fig. 2.1 Generic organizational fundraiser model choice framework 


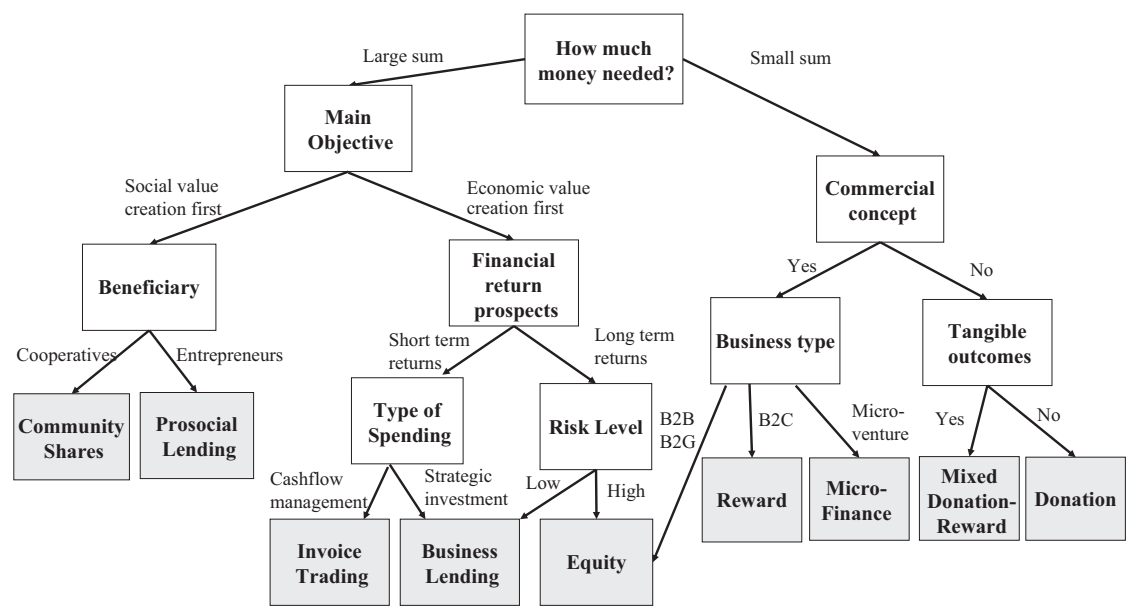

Fig. 2.2 Extended organizational fundraiser model choice framework

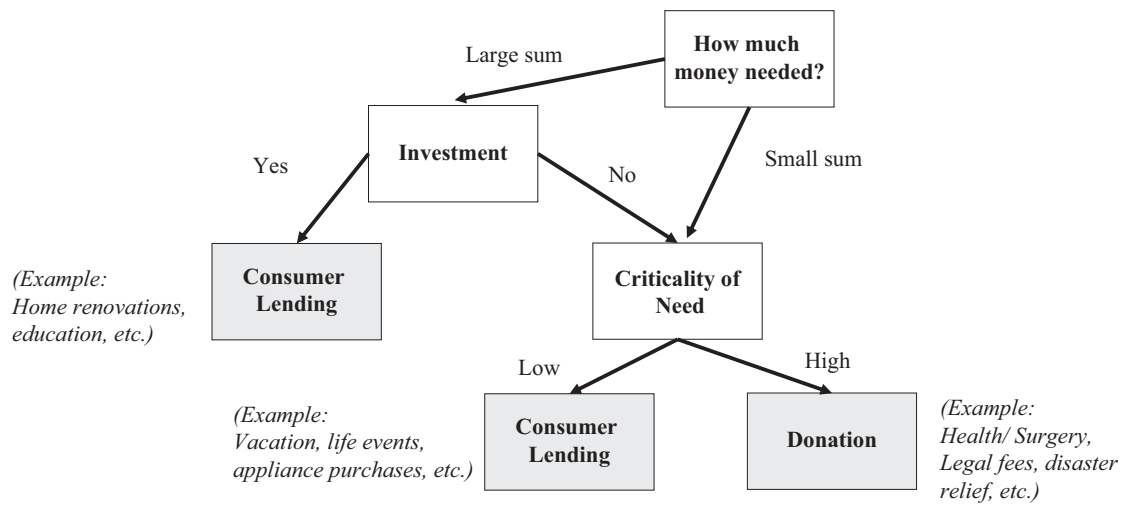

Fig. 2.3 Consumer fundraiser model choice framework

the first issue that requires addressing is an understanding of the sum needed to be raised in the campaign. Establishing such a sum should be based on a detailed project plan and budget that includes all costs expected for the execution of the project itself, the crowdfunding campaigning efforts, and a necessary buffer margin for unexpected costs. Prospective fundraisers should also consider all sources of finances necessary for project execution and the relative share of crowdfunding among these. 
Furthermore, how to use the funds raised should be meticulously planned, so that it would be easier to convey what is expected to be achieved by a successful campaign in concrete terms (i.e. number of units produced, number of employees recruited, IPR protections achieved, number of people helped, etc.). Once this is clarified, fundraisers should consider defining both their minimum goals for the fundraising efforts without which the project will not be executed, as well as some 'stretch goals' referring to what can be achieved, beyond minimum goals should the project get overfunded. Specifying stretch goals helps encouraging potential backers to contribute additional funds once minimum goals have been achieved.

Once the minimum goal sum is defined, fundraisers should evaluate whether their ambition represents a relatively small or large sum in comparison to other crowdfunding campaigns' volumes in their respective national market. Such thresholds are imprecise, vary by country, and continue to change annually as the industry develops. Hence, to best understand current local dynamics, fundraisers are encouraged to both consult experts and do some research bench-marking their own goal against earlier campaigns in the same industrial sector and country during the last few years. In very rough terms, and in most countries during 2017-2018, the threshold was between $\$ 25 \mathrm{~K}$ and $\$ 50 \mathrm{~K}$, where sums below this range can be regarded as relatively small, and above it as relatively large.

In this respect, some words of caution are warranted. First, understanding what constitutes relatively small and large sum in a certain context and point in time should not be considered as solid barriers, but rather as points of reference for calibrating expectations about likelihood of success. Crowdfunding campaigns constantly set new records, and higher sums under various models are being achieved. However, the more ambitious a campaign is, the riskier it is and the more likely it is to require additional campaigning efforts and resources.

\section{Small Sum Campaigns}

If the minimum goal sum that was set by the fundraiser falls within the range of relatively small sums, the next consideration is the very nature of the project to be funded. If the project is of a commercial nature, where, 
simply put, someone is expected to earn financially from, it is considered a business campaign. If the project is non-commercially oriented, and no one is expected to earn financially from its execution, it can be considered as a non-profit project.

Next, if the project is of a non-profit nature, the question becomes whether backers are offered tangible outcomes or benefits in the form of rewards, products or services. If no such benefits are offered, the campaigner should consider using the donation crowdfunding model. If tangible benefits are offered in a non-profit context, the fundraiser may consider a mixed reward and donation model. In such cases, funding is primarily oriented for some 'greater good' but may offer backers tangible benefits in the form of promotional goodies (e.g. caps, cups, or t-shirts promoting the project for attracting further support and funding), or products created by the individuals benefiting from the project being funded (e.g. handcraft, consumer goods, or food and drink experiences created by members of disadvantaged or marginalized social groups whose training, livelihood, or employment is created via funds raised).

However, if the project is business-oriented, the question becomes what type of products and services it is offering to produce or provide. If the products or services cater to certain segments of private consumers, in most cases the reward crowdfunding model will be recommended. Here, the fundraisers can pre-sell their products or services before incurring the costs in their actual production. Such pre-sales, through the offering of different rewards, may also help identify consumer preferences in advance in terms of design, feature inclusion, and pricing. An exception here is when the fundraiser is from an economically disadvantaged and financially marginalized background, and when the project involves a modest micro-venture with limited capacities for delivery of rewards longdistance. In such cases, online micro-finance may be the preferred crowdfunding model, and instead of products supporters can receive modest or no financial returns (which in most cases they reinvest in similar cases).

If the project is business-oriented and the products and services being crowdfunded cater to business or government customers, fundraisers should consider equity campaigning. Since industrial and institutional buyers are concerned with bulk purchases rather than individual rewards, as well as in economic viability encouraging them to contribute via equity 
crowdfunding may be more relevant than reward crowdfunding. Here, such buyers may enjoy both preferential rates in procurement, as well as potentially earning money indirectly from their own consumption of these products and services via holding an ownership stake in the supplier company.

\section{Large Sum Campaigns}

If the minimum goal sum that was set by the fundraiser falls within the range of relatively large sums, the next consideration is the very nature of the project to be funded. If the project funded is primarily expected to generate non-financial returns, it is considered as offering social returns. 'Social returns' is used here as an umbrella term for social, humanitarian and environmental benefits. If the project funded is primarily aimed at generating financial returns, it is considered as offering an investment opportunity.

When projects primarily offer social returns, the question becomes who the main beneficiary of such benefits is. If the project is likely to benefit a group of people with a common social mission and need (for example_village installing windmills or solar panels for resident electricity consumption), they may organize themselves as a cooperative society, while selling ownership shares in the cooperative to its prospective members. However, if the project is likely to benefit entrepreneurs creating social ventures that are primarily concerned with social returns, and financial returns represent secondary concerns, such fundraisers may consider various formats of pro-social lending (e.g. start-up for plastic collecting and recycling that employs unemployed people while cleaning up natural reserves and waterbodies).

When projects primarily offer financial returns from a pure commercial activity, the question becomes what the expected time horizon until backers receive such benefits is likely to be. If the project entails longterm investments, the question again becomes what level of risk is involved. If risks are relatively low, and sufficient cashflows from the project are highly likely, the fundraising venture should consider using a business lending model. However, if risks are relatively high, and cashflow 
timing and volumes are more uncertain, fundraisers should consider using an equity crowdfunding model by selling ownership stakes in the venture.

Alternatively, if the project entails short-term investments for potential backers, the question becomes how the funding raised will be spent. If funding is used for a strategic investment towards firm enhanced capacities and growth, fundraisers should consider using a business lending model. However, if the funding is used for managing healthier cash-flows, and the firm already has sales, fundraisers should consider using invoice trading.

\section{Consumption-Oriented Campaigns}

In addition to organizational fundraisers, a large proportion of crowdfunding volumes is associated with financing consumers. In this context, the model options are more limited, but the volumes are substantial, as shown in the CCAF reports (Ziegler et al. 2018a, b, 2019; Zhang et al. 2018) throughout recent years. However, it is worth noting that while a large portion of such loans is indeed associated with consumption, some of it also camouflages early-stage venturing by single entrepreneurs taking consumer loans to fund their business startup activities.

Here, again, the first aspect to be considered is the amount of money sought. Consumers need to plan for costs associated with the consumption activity they are planning to engage in, as well as the costs associated with the crowdfunding activity. Once such costs are clarified in advanced, a minimum goal sum for a campaign may be set. Once such a sum is defined, fundraisers should evaluate whether their ambition represents a relatively small or large sum in comparison to other consumer crowdfunding campaigns' volumes in their respective national market. As in organizational crowdfunding, such thresholds are imprecise, vary by country, and continue to change annually as the industry develops. Here as well, fundraisers are encouraged to both consult experts and do some research bench-marking their own goal against earlier campaigns with similar goals, which took place in the same country and during the last few years. In very rough terms, and in most countries during 2017-2018, the threshold was between $\$ 5 \mathrm{~K}$ and $\$ 10 \mathrm{~K}$, where sums below this range can be regarded as relatively small, and above it as relatively large. 
If the minimum goal sum that was set by the fundraiser falls within the range of relatively small sums, the next consideration is how critical the funding is to the well-being of the fundraiser. If the funding is very critical for the well-being of the fundraisers (e.g. health or surgery emergencies, payment of legal fees, disaster relief), they should consider a donation crowdfunding model. However, if the funding is not critical to the well-being of the fundraiser as in the cases of regular consumption (e.g. life events such as weddings or birthdays, purchase of home appliances, home renovations and upgrades), fundraisers should consider consumer lending models.

If the minimum goal sum that was set by the fundraiser falls within the range of relatively large sums, the next consideration is how would the funds raised be used. If the funding will be used for investment in physical or human capital (e.g. home renovations and upgrades, education procurement), fundraisers should consider using a consumer lending model. If large sums will be used for consumption rather than investment, the concern for the criticality of funding for the fundraiser's wellbeing emerges again, and the choice of models follows that described earlier.

\section{Conclusion}

In the current chapter all crowdfunding models that have been employed in recent years have been defined and their characteristics outlined. Furthermore, the chapter presents novel frameworks guiding both organizations (including those involving one-man operations) and consumers through a decision-making process towards choosing the model that best fits their funding needs and characteristics. In this sense, the chapter's main contributions are in both presenting one of the most elaborate, upto-date, and detailed typologies for crowdfunding models currently in use, and in being the first to suggest frameworks for systematic choicemaking between models by fundraisers.

Nevertheless, the current chapter has some limitations that also present opportunities for further research. First, the characterization of models that were presented in terms of success rates, onboarding rates, and risk levels capture current dynamics, understanding, and knowledge. 
However, since the industry is young and dynamic, and since some evidence for regional differences does exist, these should be revisited and tested empirically in future studies capturing the state of the market at more advanced levels of maturation, and across national and regional markets. Second, the suggested frameworks that were outlined follow a prescriptive and normative nature based on the accumulated experience of working with the industry from its early days til now. However, as such, it represents a certain set of heuristics that may guide prospective fundraisers, but it is not the only relevant set of such heuristics. Accordingly, future studies may seek to both empirically validate the decision process outlined, as well as further develop and amend it in a systematic data collection and analysis efforts (both qualitatively and quantitatively). Third, the organizational model choice frameworks suggested do not differentiate between different kinds of organizations in terms of size, age, or popular awareness. Accordingly, it may be interesting for future researchers to investigate whether model choice heuristics differs by such organizational characteristics.

Finally, the information and frameworks presented in this chapter also have several implications for practice. In this context, prospective fundraisers may consult the typology, model characteristics, and the outlined model choice frameworks and use them in their own fundraising decision making efforts. Furthermore, these may also be used by educators and trainers that wish to introduce crowdfunding to both students and practitioners as roadmaps for navigating through the multiple models available, while providing initial guidance into choosing between them for different project purposes.

\section{References}

Ahlers, G. K. C., Cumming, D., Günther, C., et al. (2015). Signaling in Equity Crowdfunding. Entrepreneurship Theory and Practice, 39(4), 955-980. Allison, T. H., Davis, B. C., Short, J. C., et al. (2015). Crowdfunding in a Prosocial Microlending Environment: Examining the Role of Intrinsic Versus Extrinsic Cues. Entrepreneurship Theory and Practice, 39(1), 53-73. 
Belleflamme, P., \& Lambert, T. (2016). An Industrial Organization Framework to Understand the Strategies of Crowdfunding Platforms. In J. Méric, I. Maque, \& J. Brabet (Eds.), International Perspectives on Crowdfunding: Positive, Normative, and Critical Theory. Bingley: Emerald Group Publishing Limited.

Belleflamme, P., Lambert, T., \& Schwienbacher, A. (2013). Individual Crowdfunding Practices. Venture Capital, 15(4), 313-333.

Cumming, D. J., Leboeuf, G., \& Schwienbacher, A. (2019a). Crowdfunding Models: Keep-It-All vs All-Or-Nothing. Financial Management, https:// onlinelibrary.wiley.com/doi/abs/10.1111/fima.12262.

Cumming, D. J., Hornuf, L., Karami, M., et al. (2019b). Disentangling Crowdfunding from Fraud Funding, May 16, 2019. Retrieved from https:// onlinelibrary.wiley.com/doi/abs/10.1111/fima.12262.

De Buysere, K., Gajda, O., Kleverlaan, R., et al. (2012). A Framework for European Crowdfunding. Retrieved from https://www.fundraisingschool.it/ wp-content/uploads/2013/02/European-Crowdfunding-FrameworkOct-2012.pdf.

Dorfleitner, G., \& Oswald, E.-M. (2016). Repayment Behavior in Peer-to-Peer Microfinancing: Empirical Evidence from Kiva. Review of Financial Economics, 30, 45-59.

Dorfleitner, G., Rad, J., \& Weber, M. (2017). Pricing in the Online Invoice Trading Market: First Empirical Evidence. Economics Letters, 161, 56-61.

Emekter, R., Tu, Y., Jirasakuldech, B., et al. (2015). Evaluating Credit Risk and Loan Performance in Online Peer-to-Peer (P2P) Lending. Applied Economics, 47(1), 54-70.

Gajda, O. (Ed.). (2017). Review of Crowdfunding Regulation: Interpretations of Existing Regulation Concerning Crowdfunding in Europe North America and Israel. Brussels: European Crowdfunding Network AISBL.

Gray, M., \& Zhang, B. (2017). Crowdfunding: Understanding Diversity. In R. Martin \& J. Pollard (Eds.), Handbook on the Geographies of Money and Finance. Cheltenham: Edward Elgar Publishing.

Haas, P., Blohm, I., \& Leimeister, J. M. (2014). An Empirical Taxonomy of Crowdfunding Intermediaries. In International Conferences of Information Systems 2014, Auckland, New Zealand.

Hainz, C. (2018). Fraudulent Behavior by Entrepreneurs and Borrowers. In D. Cumming \& L. Hornuf (Eds.), The Economics of Crowdfunding: Startups, Portals and Investor Behavior. Cham: Springer International Publishing. 
Lin, X., Li, X., \& Zheng, Z. (2017). Evaluating Borrower's Default Risk in Peerto-Peer Lending: Evidence from a Lending Platform in China. Applied Economics, 49(35), 3538-3545.

Méric, J., Maque, I., \& Brabet, J. (2016). A Cartography of the Academic Literature on Crowdfunding. In J. Méric, I. Maque, \& J. Brabet (Eds.), International Perspectives on Crowdfunding: Positive, Normative and Critical Theory. Bingley: Emerald Group Publishing Limited.

Mollick, E. (2015a). Delivery Rates on Kickstarter, December 4, 2015. Retrieved from https://ssrn.com/abstract=2699251.

Mollick, E. (2015b). The Kickstarter Fulfillment Report [Online]. Kickstarter. com. Retrieved April 30, 2019, from https://www.kickstarter.com/fulfillment. Schreiner, M. (2001). Informal Finance and the Design of Microfinance. Development in Practice, 11(5), 637-640.

Shneor, R., \& Flåten, B.-T. (2015). Opportunities for Entrepreneurial Development and Growth Through Online Communities, Collaboration, and Value Creating and Co-creating Activities. In H. R. Kaufmann \& S. M. R. Shams (Eds.), Entrepreneurial Challenges in the 21st Century. Basingstoke: Palgrave Macmillan.

Signori, A., \& Vismara, S. (2016). Returns on Investments in Equity Crowdfunding, April 10, 2016. Retrieved from https://ssrn.com/ abstract $=2765488$.

Swords, J. (2017). Crowd-Patronage-Intermediaries, Geographies and Relationships in Patronage Networks. Poetics, 64, 63-73.

Wang, Z., Jiang, C., Ding, Y., et al. (2018). A Novel Behavioral Scoring Model for Estimating Probability of Default Over Time in Peer-to-Peer Lending. Electronic Commerce Research and Applications, 27, 74-82.

Wenzlaff, K. \& Odorović, A. (2020). Joint Production of Confidence-SelfRegulation in European Crowdfunding Markets. Baltic Journal of Management, 15(2), https://doi.org/10.1108/BJM-04-2019-0119.

Zhang, B., Ziegler, T., Mammadova, L., et al. (2018). The 5th UK Alternative Finance Industry Report. Cambridge: Cambridge Centre for Alternative Finance.

Ziegler, T., Johanson, D., Zhang, B., et al. (2018a). The 3rd Asia Pacific Region Alternative Finance Industry Report. Cambridge: Cambridge Centre for Alternative Finance.

Ziegler, T., Johanson, D., King, M., et al. (2018b). Reaching New Heights: The 3rd Americas Alternative Finance Industry Report. Cambridge: Cambridge Centre for Alternative Finance. 
Ziegler, T., Shneor, R., Garvey, K., et al. (2018c). Expanding Horizons: The 3rd European Alternative Finance Industry Report. Cambridge: Cambridge Centre for Alternative Finance.

Ziegler, T., Suresh, K., Garvey, K., et al. (2018d). The 2nd Annual Middle East \& Africa Alternative Finance Industry Report. Cambridge: Cambridge Center for Alternative Finance.

Ziegler, T., Shneor, R., Wenzlaff, K., et al. (2019). Shifting Paradigms-The 4th European Alternative Finance Benchmarking Report. Cambridge: Cambridge Centre for Alternative Finance.

Open Access This chapter is licensed under the terms of the Creative Commons Attribution 4.0 International License (http://creativecommons.org/licenses/ by/4.0/), which permits use, sharing, adaptation, distribution and reproduction in any medium or format, as long as you give appropriate credit to the original author(s) and the source, provide a link to the Creative Commons licence and indicate if changes were made.

The images or other third party material in this chapter are included in the chapter's Creative Commons licence, unless indicated otherwise in a credit line to the material. If material is not included in the chapter's Creative Commons licence and your intended use is not permitted by statutory regulation or exceeds the permitted use, you will need to obtain permission directly from the copyright holder.

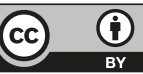

